\title{
Antibacterial Effect of Pepper and Chilli against Staphylococcus Aureus: A Comparative Study
}

\section{Anju TR*, Gopal N and Parvathy S}

Department of Botany \& Biotechnology, Newman College, India

*Corresponding author: Anju TR, Assistant Professor, Department of Biotechnology, Newman College, Thodupuzha-685585, Kerala, India, Tel: +919446002071; Email: anju.tr@newmancollege.ac.in/ anjutr@gmail.com

\section{Research Article}

Volume 4 Issue 3

Received Date: May 20, 2019

Published Date: June 03, 2019

DOI: $10.23880 / \mathrm{ijbp}-16000162$

\section{Abstract}

Pepper (Piper nigrum) and green chilli (Capsicum annum var glabriusculum) are routinely used in Indian culinary as flavouring agents. Even though the use of green chilli is more prominent in dishes, pepper has been traditionally used as an important spice in Kerala since decades. In addition, Pepper is an inevitable component in many home made decoctions using herbals for upper respiratory tract infections. Keeping this in mind, the present study is designed to investigate the antimicrobial potential of these two spices to evaluate whether the use of pepper can impart any selective advantage over green chilli. To study the antimicrobial potential of Piper nigrum and Capsicum annum var glabriusculum, we selected Staphylococcus aureus, a commensal of the human microbiota which can act as an opportunistic pathogen. Staphylococcus aureus was isolated from soil microfauna by serial dilution and plating techniques. Strain identification was done by various biochemical and morphological tests and strain confirmation was done by 16SrRNA genome sequencing. Pure cultures of Staphylococcus aureus were maintained by subculturing and used for studying the antimicrobial effects of Piper nigrum and Capsicum annum var glabriusculum using disk diffusion method. Both Piper nigrum and Capsicum annum var glabriusculum showed a clear zone of inhibition around the disk in four separate experiments with a mean value of $2.05 \mathrm{~cm}$ and $1.70 \mathrm{~cm}$ respectively. The comparative analysis of the inhibition zone by statistical software Graphpad Instat showed a significantly higher $(\mathrm{p}=0.02)$ inhibition zone in Piper nigrum than Capsicum annum var glabriusculum. This points to the selective advantage of pepper components over green chilli in controlling Staphylococcus aureus, thus scientifically validating the health benefits of pepper over chilli. Since maintaining the probiotics is also important, identifying the entire microbial fauna affected by these extracts are important to suggest a better spice for food, which is the future prospect for research in this direction.

Keywords: Piper Nigrum; Capsicum Annum Var Glabriusculum; Disk Diffusion 


\section{International Journal of Biochemistry \& Physiology}

\section{Introduction}

Antimicrobial properties of the phytochemicals or natural therapeutics were notable alternative to modern antibiotic drugs. Recent clinical report suggests that most of the microorganisms were developing resistance to many commonly used antibiotics because of the improper protocol of antibiotics prescriptions [1]. Hence scientific community is showing interest in the use of photochemical and nutritional supplements as agents to cure many diseases. Plant extracts and secondary metabolites possess antimicrobial, antifungal or antiviral activities. Various plant products regularly used for their therapeutic potential, and plant products that form the part of the food or as dietary components, have been receiving considerable attention. Though much is known about the chemistry and antimicrobial action of several phytochemicals, very few reports are available on the possible use of nutritional supplements in this regard.

Piper nigrum (Black pepper/ Pepper) commonly known as the King of spices due to its pungent quality [2] is a member of family Piperaceae [3-5]. Dried ground pepper has been used since antiquity both for its flavour and as a traditional medicine. Black pepper is the world's most traded spice, and is one of the most common spices added to cuisines around the world. Its spiciness is due to the chemical piperine. It is ubiquitous in the modern world as a seasoning and is often paired with salt. Black pepper can be used for different purposes such as human dietaries, as medicine, as preservatives, as biocontrol agents $[2,6,7]$. This plant and its active component piperine can stimulate the digestive enzymes of pancreas and intestine and also increases biliary bile acid and secretion when administrated orally [8]. Piperine prevents and minimize diarrhea produced by various oils and chemicals and also reduce intestinal fluid in mouse intestine [9].

P. nigrum has anti- inflammatory activity, thermogenic action, growth regulatory activity, anti-thyroid activity and chemopreventive [10]. Secondary metabolites from $P$. nigrum are reported to play defensive role against infection by microbes, insects and animals [4]. Medicinally black pepper can be used for digestive disorders like large intestine toxins, different gastric problems, diarrhea, and indigestion and also can be used against respiratory disorders including fever, cold, asthma [11].

Capsicum annum var glabriusculum is a domesticated species of plant genus in the family solanaceae [12]. Foods containing peppers, especially chili peppers, often have a strong aftertaste which is due to the presence of capsinoids in peppers [13]. They are rich sources of vitamin $\mathrm{C}$ (ascorbic acid) and vitamin $\mathrm{A}$. In addition to the use of capsicum fruits as a food additive, in traditional medicine, it has been used for the treatment of parasitic infections, rheumatism, and wound healing [14] and also utilized as an antiseptic, counterirritant, appetite stimulator [15], antioxidant and immunomodulator [16]. The medicinal effects of chilies are related to different constituents such as capsaicin, fixed oil, thiamine, protein and ascorbic acid [15].

P. nigrum and Capsicum fruitscence are commonly used spices in most of the food preparations in daily life. There is a common belief among different community of people regarding the magical effect of these spices in preventing or curing diseases. But a clear scientific backup for these ideas are lacking and hence we check their antimicrobial activity against a common pathogenic bacteria Staphylococcus aureus.

Staphylococcus aureus (S. aureus) belongs to the family micrococcaceae family and causes a wide range of infections from a variety of skin, wound and deep tissue infections to more life-threatening conditions such as pneumonia, endocarditis, septic arthritis and septicemia. This bacterium is also one of the most common species in nosocomial infections. In addition, $S$. aureus may also cause food poisoning, scalded-skin syndrome and toxic shock syndrome, through production of different toxins. Since $S$. aureus is an opportunistic pathogen, we selected this strain for testing the antimicrobial property of the two spices which forms our regular dietary supplements.

The present investigation is aimed to identify the broad spectrum antimicrobial activity of $P$. nigrum and Capsicum extracts against $S$. aureus. To achieve this goal, the bacterial strain was isolated from soil sample and characterised by various standardized protocols. This bacterium was used for studying the antimicrobial activity of P. nigrum and Capsicum by disk diffusion method. A systematic analysis like this is expected to give an idea about the antimicrobial effects and the relative efficiency among the two species selected for the study.

\section{Materials and Methods}

Eight soil samples were collected from different sites and locations of Thodupuzha, Kerala, India. Soil samples were collected at a depth of $0.75 \mathrm{~m}$ from the surface. The samples collected were serially diluted and streak plated on nutrient agar for the purification and separation of colonies. 


\section{International Journal of Biochemistry \& Physiology}

\section{Biochemical Test and Strain Identification}

Microbial strain was confirmed using the histological and various biochemical tests like gram staining, catalase test, citrate test, motility test and Glucose fermentation. Strain was identified by colony characteristics in mannitol salt agar (MSA) and 16srRNA genome sequencing.

\section{Plant Specimen and Extract Preparation}

Seeds of Piper nigrum and Capsicum annnuum var. glabriusculum are used as plant specimens to evaluate their antimicrobial activity against Staphylococcus aureus. The plant parts were collected from Karimannoor panchayat at Idukki district, Kerala, India in the month of September. The seeds were cleaned and dried and made into homogeneous powder by grinding. Solvent extraction method was used to extract the active components from the powder. The plant extract was prepared as per the protocol of Pavan, et al. [17].

\section{Antimicrobial Activity by Disk Diffusion Method}

Disk diffusion method was carried out to check the antimicrobial activity of Piper nigrum and Capsicum annuum var.glabriusculum extract as per the protocol of
Perez, et al. [18]. The zone of inhibition was noted for both extracts to understand the antimicrobial effects.

\section{Statistics}

All the experiments were repeated three times and significance was checked by one way ANOVA.

\section{Result}

\section{Identification and Characterization of Bacterial Strain}

The soil samples collected from different parts were used for isolation of pure bacterial strain by serial dilution. Staphylococcus aureus was identified and characterized with the help of morphological characteristics, biochemical test and 16SrRNA genome sequencing.

\section{Morphological and Biochemical Identification}

Morphological and biochemical test suggested that the isolated strain of microorganism is Staphylococcus aureus (Table 1, Figures 1- 4).

\begin{tabular}{|c|c|c|c|}
\hline S No. & Characteristics & Observations & Result \\
\hline 1 & Gram staining & Violet coloured cocci & Positive \\
\hline 2 & Catalase test & Efferevence & Positive \\
\hline 3 & Citrate test & Colour change from green to blue & Positive \\
\hline 4 & Motility test & No motility & Negative \\
\hline 5 & Glucose fermentation & Colour change from red to yellow without gas formation & Positive \\
\hline 6 & Mannitol Salt agar morphology & Yellow colonies with yellow medium & Positive \\
\hline
\end{tabular}

Table1: Morphological and Biochemical characteristics of microbial strain taken for the study.

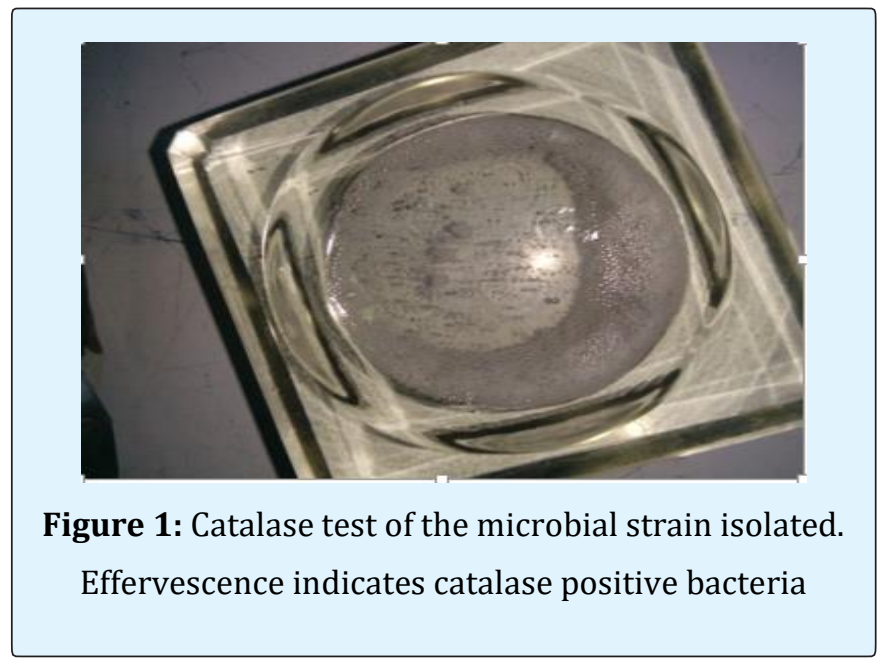

Anju TR, et al. Antibacterial Effect of Pepper and Chilli against Staphylococcus Aureus: A Comparative Study. Int J Biochem Physiol 2019, 4(3): 000162.

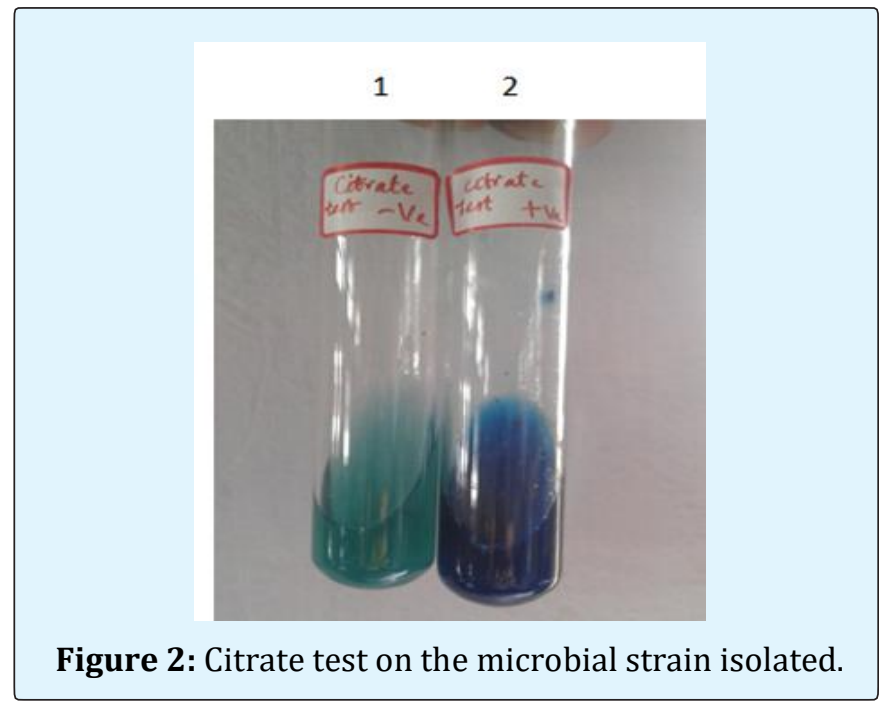

Figure 2: Citrate test on the microbial strain isolated. 


\section{International Journal of Biochemistry \& Physiology}

Results from Negative control tube (tube 1; without culture) and test sample (tube 2; with Culture) showed that the strain isolated was citrate positive.

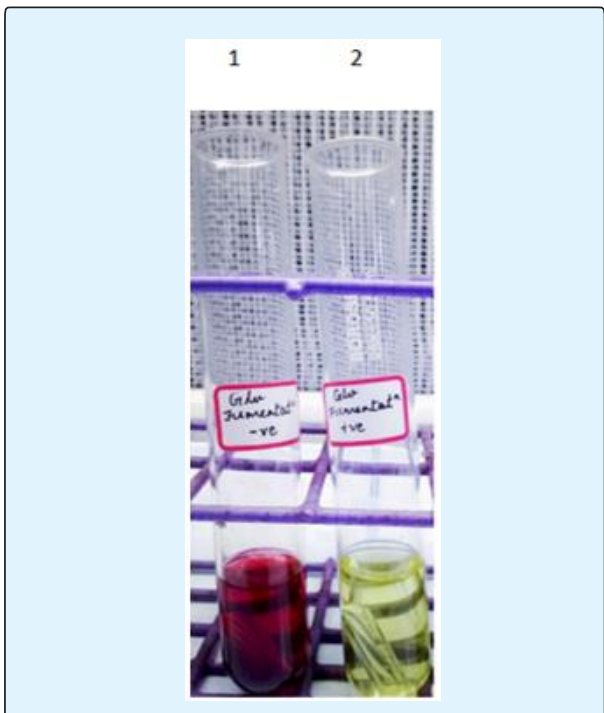

Figure 3: Glucose Fermentation test.

Negative control tube (tube 1; without culture) showed no fermentation of glucose and hence color of indicator dye phenol red is observed where as in test sample (tube 2; with culture) glucose fermentation was observed without gas production.

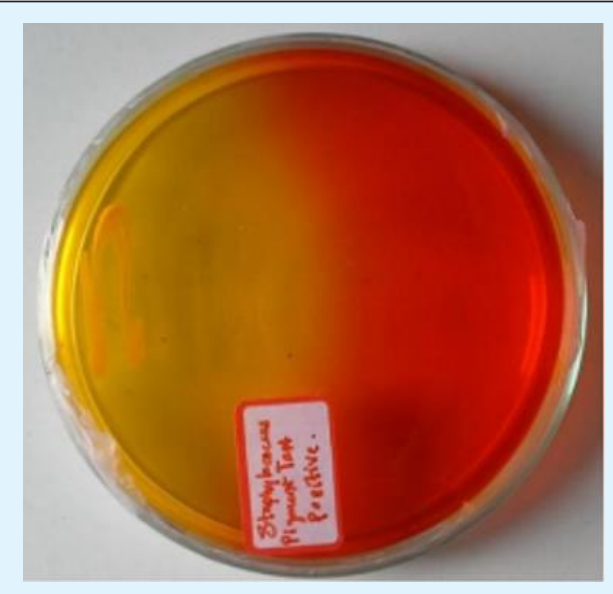

Figure 4: Colony morphology in Mannitol Salt Agar.

Yellow colonies with color change of media from red to yellow were observed in the streaked region.

\section{6srRNA Genome Sequencing}

The isolated bacterial strain was identified as Staphylococcus aureus from the data obtained from 16srRNA genome sequencing. The sequencing result showed that the isolated strain was similar to Staphylococcus aureus strain ATCC 12600 (NCBI Reference Sequence: NR_118997.2).

\section{Antimicrobial Activity of Piper Nigrum and Capsicum Annuum Var.Glabriusculum against Staphylococcus Aureus}

The zone of inhibition was measured to evaluate antimicrobial activity. Disk diffusion method was used to measure the zone of inhibition against Staphylococcus aureus. We observed a mean inhibition zone $2.05 \mathrm{~cm}$ for Piper nigrum and $1.70 \mathrm{~cm}$ for Capsicum annuum var.glabriusculum extract against Staphylococcus aureus (Table 3). No inhibition was observed in the negative control with solvent alone and hence the effect of solvent on the inhibition of $S$. aureus growth is considered to be nil. The comparative analysis of the zone of inhibition of Capsicum annuum var. glabriusculum and Piper nigrum showed that there is a significant increase $(\mathrm{P}=0.02)$ in the inhibition zone of $P$. nigrum when compared to Capsicum annum (Figure 5). The data suggested that $P$. nigrum has a significantly higher antimicrobial activity than Capsicum annum against Staphylococcus aureus.

\begin{tabular}{|c|c|}
\hline Specimen & Zone of inhibition \\
\hline Piper nigrum & $2.05 \pm 0.06$ \\
\hline Capsicum annuum var glabriusculum & $1.700 \pm 0.09$ \\
\hline
\end{tabular}

Table 3: Zone of inhibition of Capsicum annuum var glabriusculum.

Values are mean of 4 separate experiments $(n=4)$

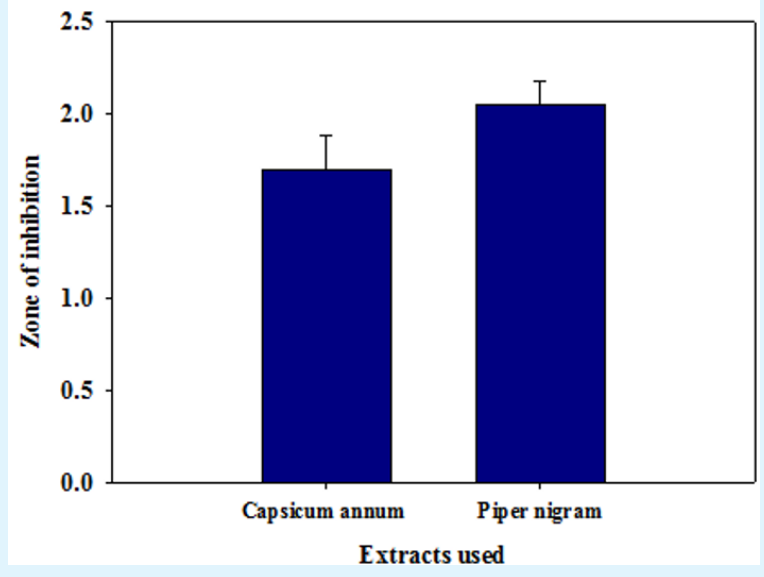

Figure 5: Comparison of zone of inhibition of Capsicum annum var glabriusculum and Piper nigrum

$P$ value is 0.02 and hence there is significant difference between the groups. 


\section{International Journal of Biochemistry \& Physiology}

\section{Discussion}

Many plant derived molecules have shown a promising effect in therapeutics. Spices are recognised as source of natural antioxidants and thus play an important role in the chemo preservation of diseases and ageing. Among plants investigated to date, the enormous potential of Piper nigrum is reported. Here, we investigated the antimicrobial activity of acetone extract of Piper nigrum and Capsicum annum var.glabriusculum on Staphylococcus aureus. In the present study, the bacterial strain isolated from soil microfauna was identified on the basis of cultural, microscopic, morphological and16S rRNA genome sequencing data.

The result of our study showed the inhibitory effect of Capsicum annum var.glabriusculum on S. aureus as evident from a clear zone of inhibition of $1.700 \mathrm{~cm}$ around the disc. Previous studies revealed that $C$. annuum var.glabriusculum have strong antimicrobial activity against Vibrio cholera, a gram negative Enterobacteriaceae [19]. The aqueous and isopropanol extracts of Capsicum species is found to be effective against Salmonella and Pseudomonas [20]. It is also reported that the aqueous extract from fresh Capsicum species showed varying degree of inhibition against Bacillus, Salmonella, Streptococcus and Clostridium spp [21]. Rose Koffi-Nevry, et al. [22] reported that flavanoids and other active components like capsaicin have potential antibacterial activity as it is major compound from Capsicum species. Based on previous studies we assumed that in the present study, the flavanoids or capsaicin might have contributed the anti-microbial activity of capsicum extract against $S$. aureus.

Piper nigrum showed a prominent zone of inhibition of $2.05 \mathrm{~cm}$ diameter by disk diffusion method against $S$. aureus. Previous studies reported the excellent inhibitory effect of acetone extract of black pepper on the growth of Gram positive bacteria [23]. Here, we found that $P$. nigrum can also show an effective inhibition of the growth of $S$. aureus too.

The present work also revealed that the effectiveness of $P$. nigrum against $S$. aureus was higher than that of the C.annuum var glabriusculum extract. From the study we can conclude that both P. nigrum and Capsicum annuum var glabriusculum extracts are effective against the growth of $S$. aureus with $P$. nigrum showing a significantly higher antimicrobial activity than Capsicum annuum var glabriusculum.
To conclude our results, we clearly observed and validated the inhibition of Staphylococcus aureus growth by both Piper nigrum and Capsicum annum var glabriusculum extracts invitro. Further analysis of the data by statistical tools showed the more potent effects of Piper nigrum than Capsicum annum var glabriusculum against Staphylococcus aureus. This can be considered as a first report on the comparative analysis of two commonly used spices in diet to address the question of overall health benefits which can be impacted by them. Further study in this direction will help in proving that the Queen of spices - black pepper - is not only a delicacy in Indian culinary but a health booster and prophylactic too.

\section{Acknowledgement}

The authors acknowledge Newman College, Thodupuzha for providing the infrastructural facilities to conduct the work. This work was supported by the grant from KSCSTE, Govt. of Kerala under SPYTiS-II programme to Dr. Anju T R \& Neethu Gopal.

\section{References}

1. Arias CA, Murray BE (2015) A New Antibiotic and the Evolution of Resistance. New England Journal of Medicine 372(12): 1168-1170.

2. Srinivasan K (2007) Black pepper and its pungent principle-piperine: A review of diverse physiological effects. Crit Rev Food Sci Nutr 47(8): 735-748.

3. Nair RR, Gupta SD (2003) Somatic embryogenesis and plant regeneration in black pepper (Piper nigrum L.): Direct somatic embryogenesis from tissue of germinating seeds and ontogeny of somatic embryos. J Hortic Sci Biotchnol 78(3): 416-421.

4. Ahmad N, Fazal H, Abbasi BH, Rashid M, Mahmood T, et al. (2010) Efficient regeneration and antioxidant potential in regenerated tissues of Piper nigrum L. Plant Cell, Tissue and Organ Culture 102(1): 129-134.

5. Abbasi BH, Ahmad N, Fazal H, Mahmood T (2010) Conventional and modern propagation techniques in Piper nigrum. J Med Plant Res 4(1): 7-12.

6. Awen BZ, Ganapati S, Chandu BR (2010) Influence of sapindus mukorossi on the permeability of ethyl cellulose free film for transedermal use. Res J Pharma Biol Chem Sci 1: 35-38. 


\section{International Journal of Biochemistry \& Physiology}

7. Hussain A, Naz S, Nazir H, Shinwari ZK (2011) Tissue culture of Black pepper (Piper nigrum L.) in Pakistan. Pak J Bot 43(2): 1069-1078.

8. Tiwari P, Singh D, Singh MM (2008) Antitrichomonas activity of sapindus saponins, a candidate for development as microbicidal contraceptive. J Antimicrob Chemother 62(3): 526-534.

9. Reshmi SK, Sathya E, Devi PS (2010) Isolation of piperdine from Piper nigrum and its antiproliferative activity. African J Pharma Pharmacol 4(8): 562-573.

10. Panda S, Kar A (2003) Piperine lowers the serum concentration of thyroid hormones, glucose and hepatic 5D activity in adult male mice. Horm Metab Res 35(9): 523-526.

11. Parganiha R, Verma S, Chandrakar S, Pal S, Sawarkar HA, et al. (2011) In vitro anti-asthmatic activity of fruit extract of Piper nigrum (Piperaceae). Inter J Herbal Drug Res 1: 15-18.

12. Greenleaf WH (1986) Pepper breeding. In: Basset MJ (Ed.), Breeding Vegetable Crops. AVI Publishing Company, Westport, Connecticut, USA, pp: 67-134.

13. Grubben GJH, El Tahir IM (2004) Capsicum annuum L. In: Grubben GJH, Denton OA (Eds.), PROTA 2: Vegetables/L'egumes. PROTA Foundation, Wageningen, The Netherlands.

14. Singletary K (2011) Red pepper: overview of potential health benefits. Nut Today 46(1): 33-47.

15. Pawar SS, Bharude NV, Sonone SS, Deshmukh RS, Raut AK, et al. (2011) Chilles as food, spice and medicine: a perspective. Int J Pharm Biol Sci 1(3): 311-318.

16. Maji AK, Banerji P (2016) Phytochemistry and gastrointestinal benefits of the medicinal spice,
Capsicum annuum L. (Chilli): a review. J Complement Integr Med 13(2): 97-122.

17. Pavan FR, Leite CQF, Coelho RG, Coutinho ID, Honda NK, et al. (2009) Evaluation of anti-Mycobacterium tuberculosis activity of Campomanesia adamantium (Myrtaceae). Quím Nova 32(5): 1222-1226.

18. Perez C, Paul M, Bazerque P (1990) Antibiotic assay by agar well diffusion method. Acta Biol Med Exp 15: 113-115.

19. Chatterjee S, Asakura M, Chowdhury N, Neogi SB, Sugimoto N, et al. (2010) Capsaicin, a potential inhibitor of cholera toxin production in Vibrio cholerae. FEMS Microbiol Lett 306(1): 54-60.

20. Careaga M, Fernandez E, Dorantes L, Mota L, Jaramillo ME, et al. (2003) Antibacterial activity of Capsicum extract against Salmonella typhimurium and Pseudomonas aeruginosa inoculated in raw beef meat. International journal of food microbiology 83(3): 331-335.

21. Cichewicz RH, Thorpe PA (1996) The antimicrobial properties of chile peppers (Capsicum species) and their uses in Mayan medicine. J Ethnopharmacol 52(2): 61-70.

22. Nevry RK, Kouassi KC, Nanga ZY, Koussemon M, Loukou GY (2011) Antibacterial Activity of Two Bell Pepper Extracts: Capsicum annuum L. and Capsicum frutescens. International Journal of Food Properties 15(5): 961-971.

23. Karsha PV, Lakshmi OB (2010) Antibacterial activity of black pepper (Piper nigrum Linn.) with special reference to its mode of action on bacteria. Indian Journal of Natural Products and Resources 1 (2): 213215. 